\title{
Reduction of shrinkage and brittleness for resorcinol-formaldehyde aerogels by means of a pH-controlled sol-gel process
}

René Tannert, Marina Schwan, and Lorenz Ratke

Institute of Materials Research, German Aerospace Center (DLR), 51170 Cologne rene.tannert@dlr.de; marina.schwan@dlr.de; lorenz.ratke@dlr.de Corresponding Author: René Tannert

Rene.tannert@dlr.de, tel. +49 2203601 4291, fax. +49 220368936

\section{Abstract}

Aerogels have attracted remarkable attention as porous low-density superinsulating material. However, they are typically brittle and tend to shrink during preparation or work-up preventing their use as a composite material. In that context, we have developed a sol-gel-process towards resorcinol-formaldehyde aerogels that includes a precise $\mathrm{pH}$-adjustment at an early stage of the polymerization. As a result, less brittle analogues of Pekala aerogels were obtained that resemble Pekala gels in many aspects (skeletal density, porosity, thermal properties). However, significant differences were found in terms of inner surface area and compressive modulus, which are smaller for lower $\mathrm{pH}$-values. Since $\mathrm{pH}$-adjustment leads to minimal gel shrinkage, this sol-gelprocess may be useful for the development of aerogel composites.

Keywords: Aerogels $\cdot$ Sol-Gel Process $\cdot$ Shrinkage $\cdot$ Density $\cdot$ Compressive modulus Thermal conductivity

\section{Introduction}


Due to their remarkable thermal insulation properties in conjunction with a very low bulk density and high porosity aerogels are materials with a wide range of interesting applications [1-5]. They have already proven applicability in aerospace research [6] and are under investigation as insulation material of the future in the building sector [7, 8]. Especially, the incorporation of aerogels in novel composites is in the focus of current research and development of functional materials $[5,9]$.

In 1989, Pekala and coworkers demonstrated that organic aerogels can be prepared by a base-catalyzed polycondensation of resorcinol and formaldehyde (RF aerogels) using a sol-gel process followed by drying of the solvent using supercritical carbon dioxide [10, 11]. Such aerogels were later shown to display an extremely low thermal conductivity [12].

Just as their inorganic counterparts, however, RF and related organic aerogels are typically brittle in nature which renders them difficult to handle and process [13].

In addition, aerogels prepared by the base-catalyzed route tend to shrink significantly even though supercritical drying is involved in the work-up procedure [14]. Shrinkage, however, is one of the key problems to be addressed when an aerogel is to be embedded into a composite [9].

Pekala and others have conducted first studies regarding the structure-property relationship of RF aerogels. A dependence of thermal conductivity on aerogel bulk density was described by the groups of Pekala, Fricke and coworkers with minimal thermal insulation of $0.012 \mathrm{~W} \cdot \mathrm{m}^{-1} \cdot \mathrm{K}^{-1}$ identified at a density of approximately $0.16 \mathrm{~g} \cdot \mathrm{cm}^{-3}[12,15]$

After Pekala s pioneering studies on base-catalyzed RF polymerizations, Lin and Ritter studied the influence of variations of $\mathrm{pH}$ on some properties of the resulting carbon 
xerogels. They found that a moderate acidification of the sol using nitric acid resulted in xerogels with an increased surface area, content of mesopores, and average pore volume [16]. Further studies have been published that describe the addition of acids such as perchloric acid (in acetone) [17], $\mathrm{HNO}_{3}[18]$ or acetic acid [19, 20] for the synthesis of RF aerogels. At Lawrence Livermore National Institute, a process using a combination of trimethylamine and hydrochloric acid in organic solvents was developed [21]. More recently, the Leventis group studied the use of hydrochloric acid without prior addition of base and came up with a synthetic process for RF aerogels that lasts only minutes at $80{ }^{\circ} \mathrm{C}$ in acetonitrile [22]. However, these procedures relying on the addition of acids alone typically yield aerogels with different morphology when compared to basecatalysis (lower BET surface area, bigger particles and pores) [23, 24].

Using an approach similar to that of Lin and Ritter, our research group recently prepared RF aerogels at low resorcinol concentrations $(\mathrm{R}: \mathrm{W}=0.006-0.013)$ and incorporating an acidification step into the synthetic procedure. Surprisingly, novel, highly flexible aerogels with an envelope density of $0.06-0.08 \mathrm{~g} \cdot \mathrm{cm}^{-3}$ could be prepared [25]. The synthesis and work-up procedure did not cause significant shrinkage to the aerogel monoliths enabling us to demonstrate their use as part of a composite material with Nomex ${ }^{\circledR}$ honeycombs [26].

In separate studies, it could be demonstrated that a late additional acidification step can yield RF aerogels that retain the small diameters of particles (in the nanometer range) that Pekala had described earlier yet containing macropores. These large pores allow the intermediate aquagels to withstand the gradient of capillary forces present in the evaporative drying under ambient pressure $[27,28]$.

However, a detailed investigation of structure and properties of RF aerogels prepared by $\mathrm{pH}$-adjustment of more concentrated resorcinol mixtures has hitherto been missing. 
Therefore, we prepared several $R F$ aerogels with higher solid fractions ( $R: W \geq 0.012$ ) and compared the properties of the resulting aerogels to conventional Pekala-type aerogels.

\section{Experimental}

\subsection{Materials}

Resorcinol (R) 98\% and anhydrous sodium carbonate (C) were supplied from Aldrich, aqueous solution of formaldehyde (F) $(24 \%$ w/w) from Merck. Nitric acid $(2.0 \mathrm{~N}$; standardized solution) was purchased by Alfa Aesar. Acetone (pure, technical grade) was purchased from Th. Geyer. For the synthesis deionized water (W) was used. Carbone dioxide 4.5 (purity $\geq 99.995 \%$ ) for supercritical drying was purchased by Praxair, Germany. Sealable containers for gelation $(180 \mathrm{~mL}$, polypropylene (PP) with screw-cap) and for washing (400 mL, PP, snap-cap) were purchased from VWR, Germany.

\subsection{Synthesis}

For this study we synthesized $R F$ aerogels with constant ratios of reactants $(R: F=0.5)$ and catalyst $(\mathrm{R}: \mathrm{C}=200)$, respectively. The $\mathrm{R}: \mathrm{W}$ molar ratio was varied in the range of 0.012-0.035. A total of 10 samples were prepared. For each sample resorcinol was dissolved in water at $20-22^{\circ} \mathrm{C}$ (room temperature, $r t$ ). Then, an aqueous solution of formaldehyde was added in one portion to the transparent solution followed by stirring at $r t$ for 5 min. Solid sodium carbonate $(0.5$ mol-\% with respect to resorcinol) was then added in one portion, and the resulting suspension was stirred for another 5 minutes. The resulting colorless solution was divided among two sealable polypropylene (PP) containers. These samples with unaltered $\mathrm{pH}=7.0-7.2$ we label $\mathrm{RF}_{7}$. In contrast, the $\mathrm{pH}$ - 
value of the second solution was adjusted to 6.5 by dropwise addition of an aqueous solution of nitric acid $(\mathrm{c}=2 \mathrm{M})$. The stirring was also continued for 30 minutes at 150 300 rpm using a cross magnetic stirring bar. Such samples were labeled $\mathrm{RF}_{6.5}$. After stirring for 30 min at $r t$ the samples were placed in a sealable PP container and kept seven days at $80^{\circ} \mathrm{C}$ in an oven. During gelation and curing gels $\mathrm{RF}_{6.5}$ turned opaque, dark red whereas $\mathrm{RF}_{7}$ appeared transparent dark red. After one week, the wet gel was cooled down to $r t$, transferred to a $400 \mathrm{~mL}$ PP container filled with acetone, and left for three days during which the acetone was replaced five times. The supercritical drying was carried out with $\mathrm{CO}_{2}$ in an autoclave (Eurotechnica, Germany) at $50^{\circ} \mathrm{C}$ and 83 bars for 5 days. The temperature was increased to $55^{\circ} \mathrm{C}$ and the pressure was released slowly (rate: 0.1 bar $\left.\cdot \min ^{-1}\right)$.

\subsection{Methods}

The $\mathrm{pH}$ was measured with a calibrated SevenEasy $\mathrm{pH}$ device with relative accuracy of \pm 0.01 . The microstructure of aerogels was investigated using scanning electron micrographs (Zeiss Merlin, Germany). Due to the non-conductive property of RF aerogels they were coated with gold before microscopy. The Brunauer-Emmett-Teller (BET) surface area of aerogels was determined using a TriStarII from Micromeritics,. Envelope and skeletal density were measured on a Micromeritics GeoPyc 1360 analyzer and Micromeritics AccuPyc machine, respectively. Compression tests were performed using a Latzke universal testing machine and load cells of $5000 \mathrm{~N}$. The compression was conducted at a rate of $1 \mathrm{~mm} \cdot \mathrm{min}^{-1}$. The thermal conductivity was measured with a Transient Plane Source (HotDisk TPS 2500S, Sweden) using the Kapton-coated sensor 5501 (radius: $6.4 \mathrm{~mm}$ ). Measurements were conducted 3 times with at least 20 min of relaxation time between individual measurements. 


\section{Results and Discussion}

\subsection{Properties of RF aerogels}

Aerogels prepared at $\mathrm{pH} 7$ were obtained as described before by Pekala and others. They display a dark red to purple color, expose a hard and brittle surface, and show a translucence comparable to rough glass. When the $\mathrm{pH}$ was lowered to 6.5 , however, the appearance of the resulting aerogels changed significantly: they are of (dark or light) brown color, are opaque, and exhibit haptics similar to smooth rubber. This difference in appearance is depicted in Figure 1.

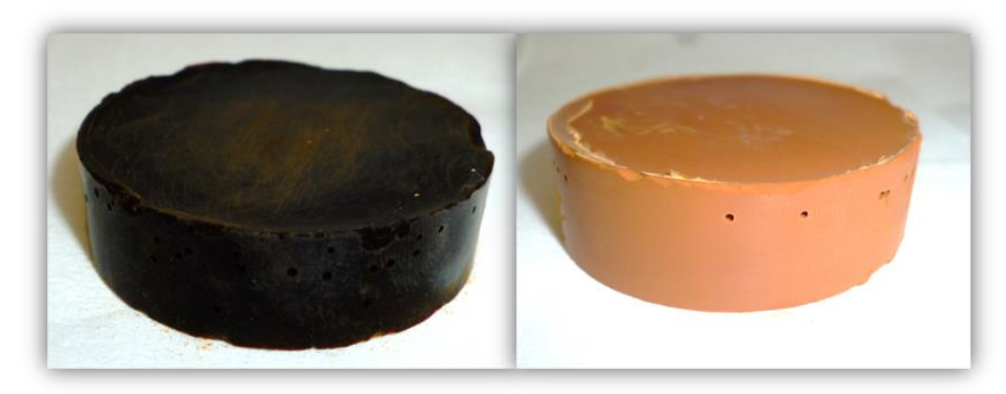

Fig. 1. Representative RF aerogels prepared at pH 7 (left) and pH 6.5 (right), respectively.

With regard to density, an increase of solid content in the synthetic procedure led to the expected increase in envelope density of the resulting aerogel as depicted in Figure 2 [29]. We observe some scatter in the data especially for aerogels prepared from solutions at a pH of 7.0 to 7.2. The source of this scatter is unclear at the moment. 


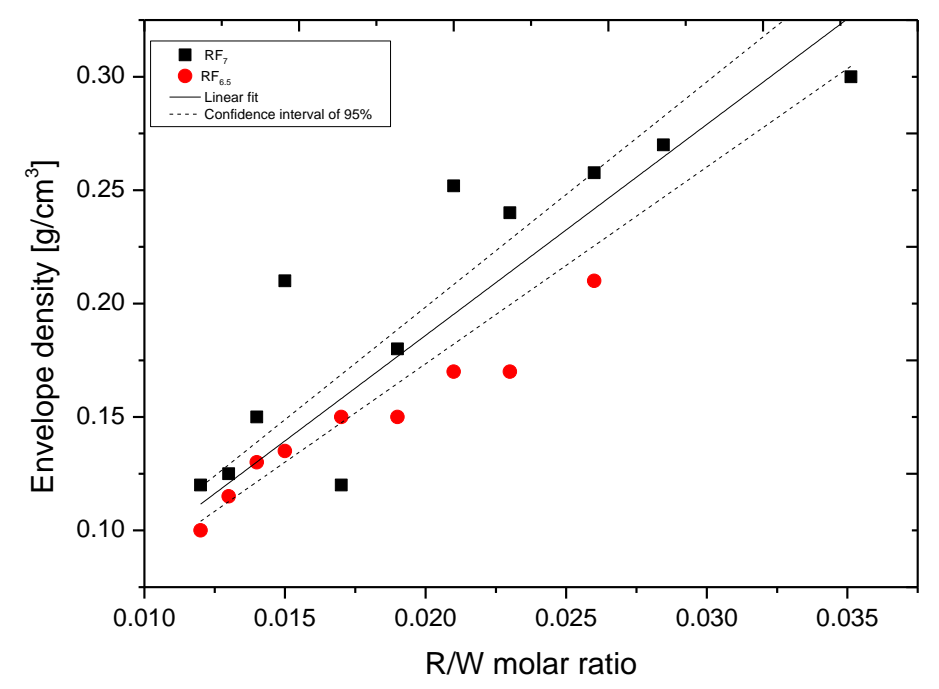

Fig. 2. Increase of envelope density with higher resorcinol

To our delight, the shrinkage of gels prepared at $\mathrm{pH} 6.5$ was significantly reduced when compared to aerogels obtained at $\mathrm{pH}$ 7. Figure 3 clearly indicates a steeper decrease of relative radial shrinkage as a function of solid content. Above R/W ratios of 0.019 an average shrinkage of less than $3 \%$ was found experimentally. Such a small degree of shrinkage can allow these aerogels to be used as part of composites such as aerogelhoneycombs [26].

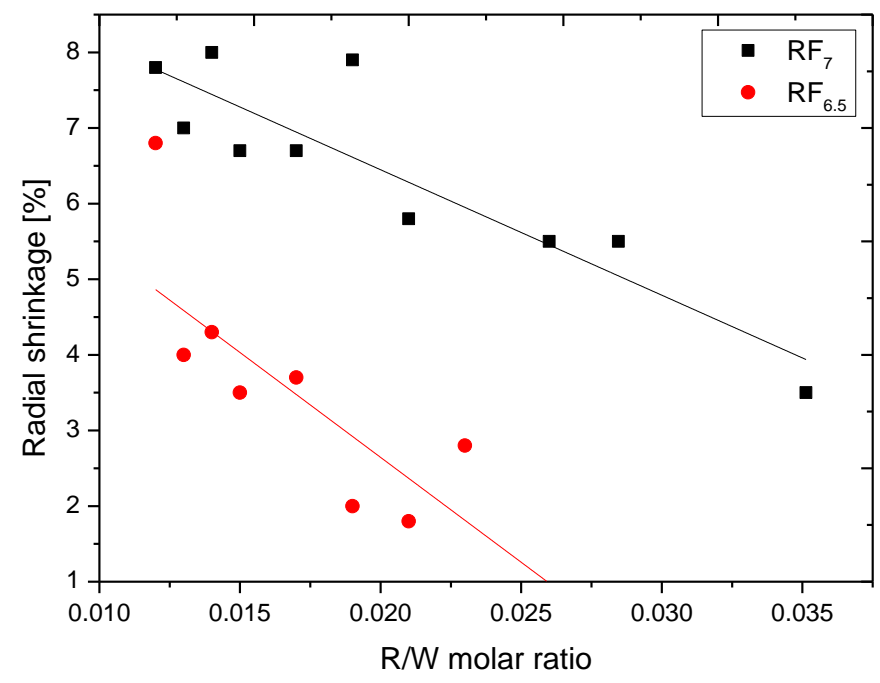


Fig. 3. Dependence of radial shrinkage on solid content. Acidified samples show less shrinkage than gels prepared at $\mathrm{pH} 7$.

\subsection{Microstructure of RF aerogels}

The microstructure of the RF aerogels was investigated qualitatively by means of scanning electron microscopy. Fig. 4 depicts micrographs of aerogels produced varying both solid content (different $\mathrm{R}: \mathrm{W}$ ) and $\mathrm{pH}$ value ( $\mathrm{pH} 7$ vs. $\mathrm{pH}$ 6.5). A micrograph of an aerogel made at $\mathrm{pH} 7$ is shown in Fig. 4-a. There, a highly homogeneous nanostructure with a large degree of crosslinking is visible. The network consists of small spherical particles which are connected in a string-of-pearl fashion. Particles of samples prepared at $\mathrm{pH}$ 6.5, on the other hand, (see Fig. 4-b) appear larger, their structure is less homogeneous, and pores are of different diameter. In general, the structure of samples prepared at pH6.5 involves larger pores and particles and shows fewer cross-links.

a) $\quad \mathrm{R}: \mathrm{W}=0.012, \mathrm{pH} 7$

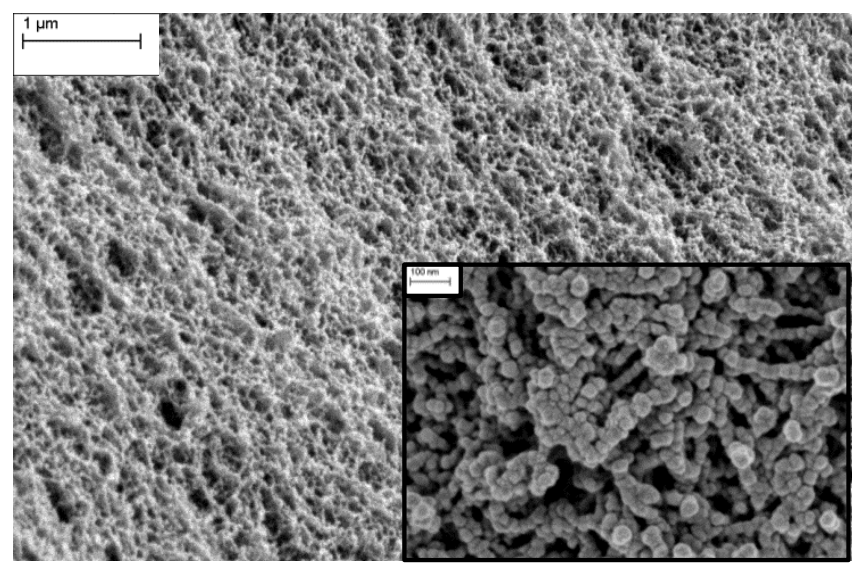

b) $\quad \mathrm{R}: \mathrm{W}=0.012, \mathrm{pH} 6.5$

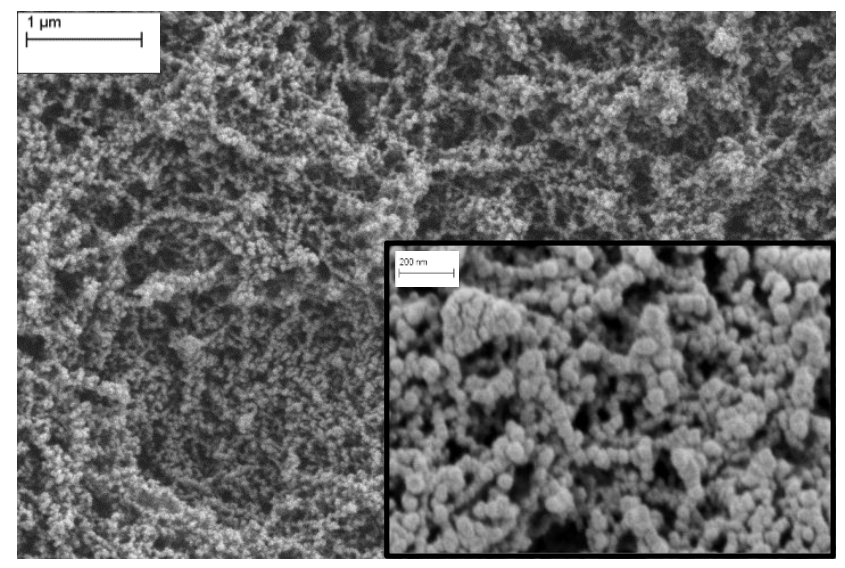


c)

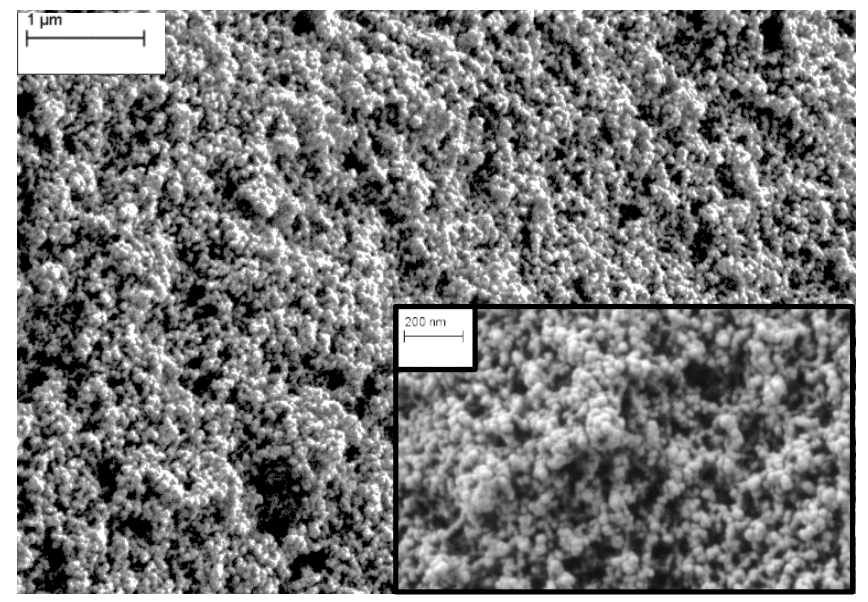

d) $\quad \mathrm{R}: \mathrm{W}=0.019, \mathrm{pH} 6.5$

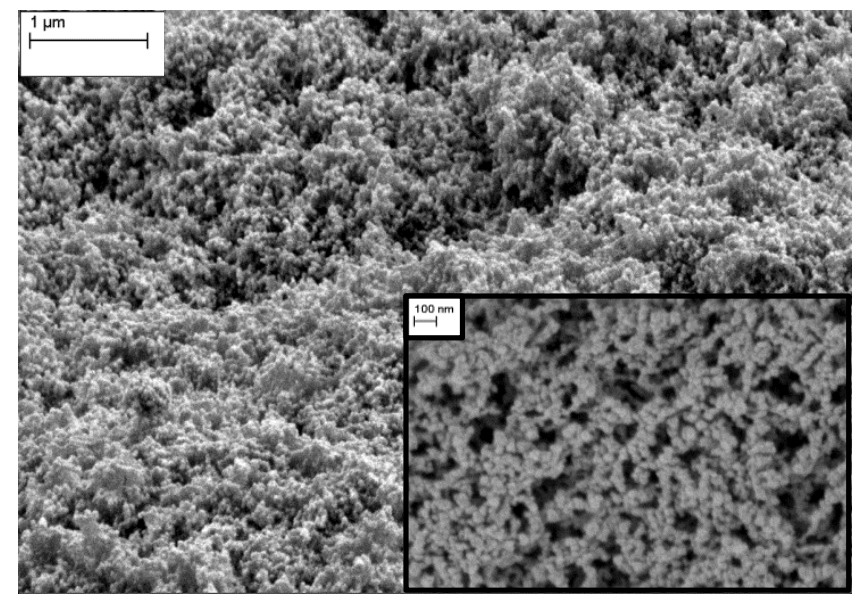

Fig. 4. Microstructure of aerogels prepared via conventional base catalysis (a and c) and base-acid catalysis (b and d).

A higher concentration of resorcinol and formaldehyde (i.e. increasing the R:W molar ratio) leads to an increase in particle size as visualized in Fig. 4 (c and d). One can see larger particles, but smaller pores, and the structures are denser and highly cross-linked. To quantify our observations we calculated the pore sizes of four aerogels using Equations (1) - (3) [30]. The porosity $\Phi$ was calculated from envelope and skeletal densities $\left(\rho_{e}\right.$ and $\left.\rho_{s}\right)$ :

$\Phi=1-\frac{\rho_{e}}{\rho_{s}}$

Since, the specific pore volume $v_{\text {pore }}$ is given by

$v_{\text {pore }}=\frac{1}{\rho_{e}}-\frac{1}{\rho_{s}}$

the average pore size $d_{a v}$ can be calculated using

$d_{\text {pore }}=\frac{4 \cdot v_{\text {pore }}}{S_{B E T}}$

Using the envelope density $\rho_{e}$ the average particle size $d_{\text {part }}$ follows from 


$$
d_{p a r t}=\frac{6 \cdot(1-\Phi)}{S_{B E T} \cdot \rho_{e}}
$$

The results are given in Table 1. Pores of aerogels prepared at $\mathrm{pH} 6.5$ are almost two times larger than those of Pekala-type aerogels prepared at $\mathrm{pH} 7$, and the pore size decreases with increasing amount of resorcinol-formaldehyde.

In the Pekala-type gel synthesis the high $\mathrm{pH}$ value is kept until gelation. There, condensation is much slower, and addition reactions dominate leading to the formation of many resole-type molecules that nucleate to form particles. Such small particles condense as "string of pearls" cross-linking eventually to form a three-dimensional network. Gels adjusted to $\mathrm{pH} 6.5$, on the other hand, are formed after an accelerated condensation of resorcinol subunits at lower $\mathrm{pH}$ values, thus resulting in fewer - yet bigger- particles growing together. Along with an increase in particle size, the pore diameter decreases (see Table 1) [27]. The particle size of aerogels prepared at $\mathrm{pH} 7$ is smaller than those prepared at higher $\mathrm{pH}$ value, confirming our estimates from SEM figures using the linear intercept method of Heyn [31, 32].

\section{Table 1}

Densities, porosity and pore size of RF aerogels as a function of resorcinol amount and $\mathrm{pH}$ value

\begin{tabular}{|c|c|c|c|c|c|c|c|c|}
\hline $\begin{array}{l}\mathrm{R}: \mathrm{W} \\
\text { molar }\end{array}$ & $\mathrm{pH}$ & $\begin{array}{l}\text { Skeletal } \\
\text { density }\end{array}$ & $\begin{array}{l}\text { Envelope } \\
\text { density }\end{array}$ & Porosity & $\begin{array}{l}\text { Pore } \\
\text { volume }\end{array}$ & $\begin{array}{l}\text { BET } \\
\text { area }\end{array}$ & $\begin{array}{l}\text { Average pore } \\
\text { diameter }\end{array}$ & $\begin{array}{l}\text { Average } \\
\text { particle size }\end{array}$ \\
\hline ratio & & {$\left[\mathrm{g} \cdot \mathrm{cm}^{-3}\right]$} & {$\left[\mathrm{g} \cdot \mathrm{cm}^{-3}\right]$} & {$[\%]$} & {$\left[\mathrm{cm}^{3} \cdot \mathrm{g}^{-1}\right]$} & {$\left[\mathrm{m}^{2} \cdot \mathrm{g}^{-1}\right]$} & {$[\mathrm{nm}]$} & {$[\mathrm{nm}]$} \\
\hline 0.012 & 6.5 & 1.49 & 0.10 & 93.3 & 9.3 & 218 & 171 & $18^{\mathrm{a}} ; 32^{\mathrm{b}}$ \\
\hline 0.012 & 7 & 1.44 & 0.12 & 91.7 & 7.6 & 507 & 60 & $8^{\mathrm{a}} ; 20^{\mathrm{b}}$ \\
\hline 0.019 & 6.5 & 1.52 & 0.15 & 90.1 & 6.0 & 364 & 66 & $11^{\mathrm{a}} ; 31^{\mathrm{b}}$ \\
\hline 0.019 & 7 & 1.42 & 0.18 & 87.3 & 4.9 & 589 & 33 & $7^{\mathrm{a}} ; 26^{\mathrm{b}}$ \\
\hline
\end{tabular}

${ }^{a}$ calculated with Equation $4 ;^{b}$ calculated from SEM images with linear intercepts of particle boundaries 
A clear trend is visible for the effect of $\mathrm{pH}$ adjustment on the internal surface area as determined by BET analysis: Irrespective of solid content, aerogels prepared using the additional acidification possess an internal surface area that is about $300 \mathrm{~m}^{2} \cdot \mathrm{g}^{-1}$ lower than that of gels prepared by the route at $\mathrm{pH} 7$.

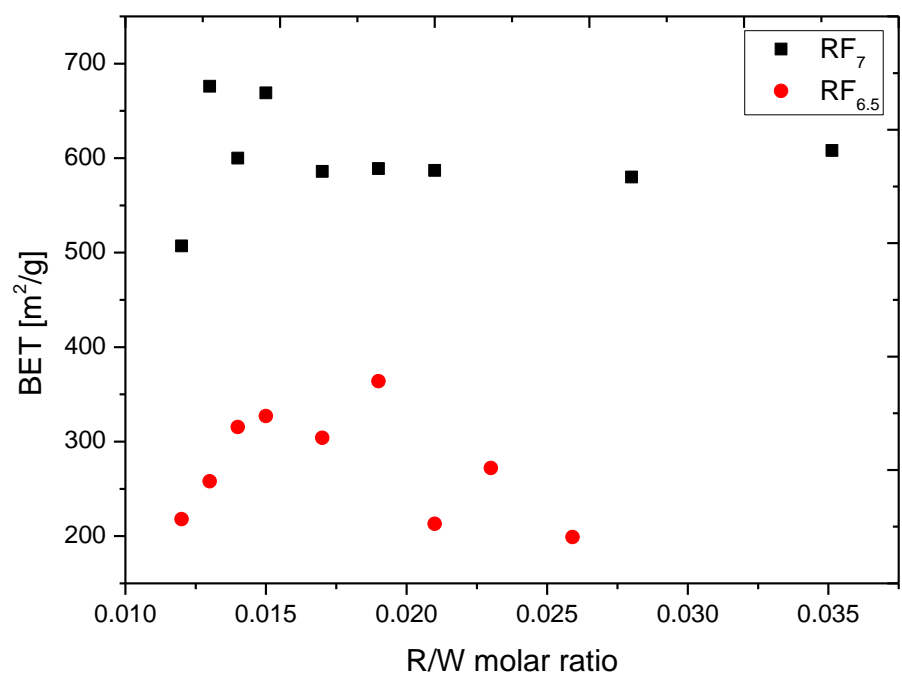

Fig. 5. Specific surface area measured by nitrogen adsorption of RF aerogels. Upon acidification the average surface area drops from $500-680 \mathrm{~m}^{2} \cdot \mathrm{g}^{-1}$ to $200-380 \mathrm{~m}^{2} \cdot \mathrm{g}^{-1}$.

\subsection{Thermal and mechanical properties}

For samples of RF aerogels prepared at $\mathrm{pH} 6.5$ thermal conductivities in a range of $0.023-0.032 \mathrm{~W} \cdot \mathrm{m}^{-1} \cdot \mathrm{K}^{-1}$ were determined. These values are similar to Pekala-type aerogels prepared at $\mathrm{pH} 7$ which ranged between 0.021 and $0.034 \mathrm{~W} \cdot \mathrm{m}^{-1} \cdot \mathrm{K}^{-1}$. A general trend is that a higher $\mathrm{R}: \mathrm{W}$ ratio leads to higher thermal conductivity due to the higher contribution of solid conductivity when the solid backbone of the aerogel increases [15]. There are, however, some inconsistent data points within this experimental row as for some of the $\mathrm{pH} 7$ samples thermal conductivities were about twice as high as Pekala, Fricke and others had reported (R:W 0.014 : density ca. $0.15 \mathrm{~g} \cdot \mathrm{cm}^{-3}, \lambda \approx 0.023 \mathrm{~W} \cdot \mathrm{m}^{-1} \cdot \mathrm{K}^{-}$ ${ }^{1}$ ). These higher values might be attributed to the measurement method used: in our 
experience, for samples with thermal conductivities below $0.03 \mathrm{~W} \cdot \mathrm{m}^{-1} \cdot \mathrm{K}^{-1}$ the Hot Disk technique applied in these studies typically results in up to $20 \%$ higher values than those obtained by a guarded hot plate method.

Table 2

\begin{tabular}{lllll}
\hline $\begin{array}{l}\mathrm{R}: \mathrm{W} \\
\text { molar } \\
\text { ratio }\end{array}$ & $\begin{array}{l}\text { Envelope } \\
\text { density } \\
\mathrm{RF}_{7}\end{array}$ & Thermal conductivity \\
{$\left[\mathrm{g} \cdot \mathrm{cm}^{-3}\right]$} & $\begin{array}{l}\text { Envelope } \\
\text { density }\end{array}$ & $\begin{array}{l}\text { Thermal conductivity } \\
\mathrm{RF}_{6.5} \\
{\left[\mathrm{~W} \cdot \mathrm{m}^{-1} \cdot \mathrm{K}^{-1}\right]}\end{array}$ & $\begin{array}{l}\mathrm{RF}_{6.5} \\
{\left[\mathrm{~W} \cdot \mathrm{m}^{-1} \cdot \mathrm{K}^{-1}\right]}\end{array}$ \\
\hline 0.012 & 0.12 & 0.021 & 0.10 & 0.030 \\
0.013 & 0.13 & 0.028 & 0.12 & 0.028 \\
0.014 & 0.15 & 0.023 & 0.13 & 0.025 \\
0.015 & 0.21 & 0.034 & 0.14 & 0.023 \\
0.016 & -- & -- & 0.15 & 0.029 \\
0.017 & 0.12 & 0.028 & $0.15 \pm 0.01^{[\mathrm{a}]}$ & $0.027 \pm 0.002^{[\mathrm{a}]}$ \\
0.019 & 0.18 & 0.025 & 0.15 & 0.031 \\
0.021 & 0.25 & 0.019 & $0.17 \pm 0.01^{[\mathrm{b}]}$ & $0.030 \pm 0.001^{[\mathrm{b}]}$ \\
0.023 & 0.24 & 0.024 & $0.17 \pm 0.02^{[\mathrm{a}]}$ & $0.030 \pm 0.002^{[\mathrm{a}]}$ \\
0.026 & 0.26 & -- & $0.21 \pm 0.04^{[\mathrm{c}]}$ & $0.032 \pm 0.004^{[\mathrm{c}]}$ \\
0.028 & 0.27 & 0.026 & -- & -- \\
0.035 & 0.30 & 0.029 & -- & -- \\
\hline
\end{tabular}

[a,b,c] Standard deviations were determined after multiple preparations of the samples: [a] 2x; [b] 7x; [c] 3x

Compression tests performed out-of-plane on aerogels prepared at $\mathrm{pH} 7$ allowed us to reproduce values for the compressive modulus (ca. $8 \mathrm{MPa}$ at a density of $0.24 \mathrm{~g} \cdot \mathrm{cm}^{-3}$ ) reported by Pekala and Kong [11].The measurements further revealed that our samples prepared from a solution at lower $\mathrm{pH}$ are less stiff than those prepared without acid catalysis. Also, the increase in stiffness as a function of solid content is much less pronounced with samples that were acidified during their synthesis (Fig.6). This lack of brittleness makes this kind of aerogel promising as part of a composite. 


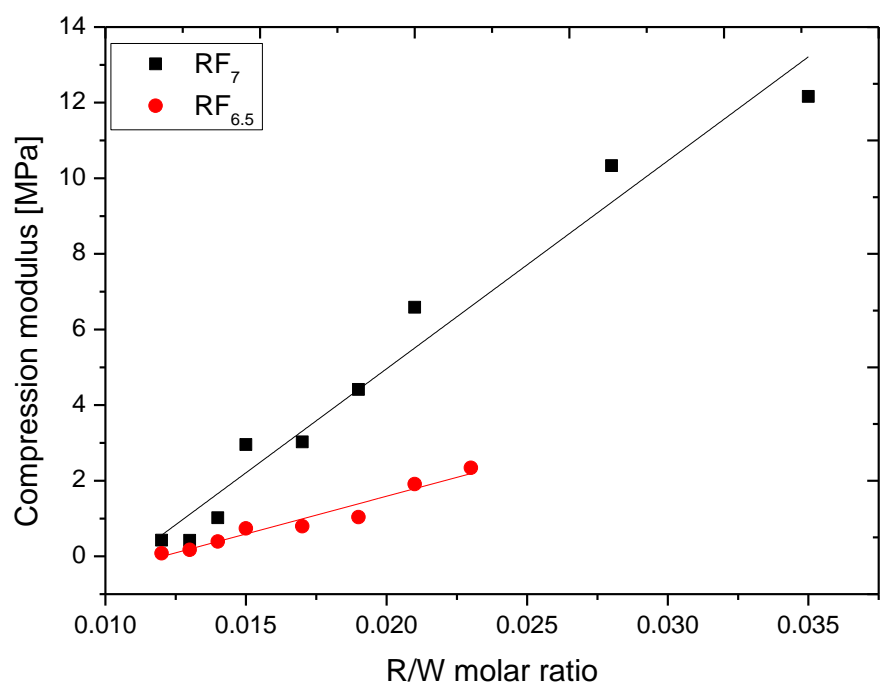

Fig. 6. Increase of compression modulus with higher R:W molar ratio.

\section{Conclusion}

$\mathrm{RF}$ Aerogels prepared by $\mathrm{pH}$ adjustment were analyzed regarding their appearance, macro- and microscopic structure, and thermal and mechanical properties. They share with Pekala-type aerogels properties such as the low density, high porosity (around $90 \%)$, and the low conductivity of heat.

Yet, there are certain properties that differ significantly: The inner surface of RF aerogels made by $\mathrm{pH}$ adjustment to a lower value of 6.5 is much smaller $\left(\approx 300 \mathrm{~m}^{2} \cdot \mathrm{g}^{-1}\right)$ whereas particles are slightly bigger and pores are about twice as wide.

Most significantly however, the new aerogels are more flexible than those prepared using only base catalysis as demonstrated by the compressive strength which is much smaller for aerogels made from solutions at $\mathrm{pH}$ 6.5. The shrinkage observed for the acidified monolithic samples after synthesis and work-up is negligible at R:W 0.019 and higher. Therefore, aerogels prepared by this route can be incorporated into composite materials such as honeycombs. Such studies are ongoing and will be published in due course. 


\section{Acknowledgment}

Funding of the Project "AeroBau" by the State of Northrhine-Westphalia is gratefully acknowledged. The authors would also like to thank Dr. Matthias Kolbe for help with the SEM images, as well as Markus Heyer for assistance with the determination of envelope density.

\section{References}

[1] H.D. Gesser, P.C. Goswami, Aerogels and related porous materials, Chemical Reviews, 89 (1989) 765-788.

[2] N. Hüsing, U. Schubert, Aerogels-Airy Materials: Chemistry, Structure, and Properties, Angewandte Chemie International Edition, 37 (1998) 22-45.

[3] A.C. Pierre, G.M. Pajonk, Chemistry of Aerogels and Their Applications, Chemical Reviews, 102 (2002) 4243-4266.

[4] M.A. Aegerter, N. Leventis, M.M. Koebel (Eds.), Aerogels Handbook, Springer New York, 2011.

[5] A. Du, B. Zhou, Z. Zhang, J. Shen, A Special Material or a New State of Matter: A Review and Reconsideration of the Aerogel, Materials, 6 (2013) 941-968.

[6] N. Bheekhun, A.R. Abu Talib, M.R. Hassan, Aerogels in Aerospace: An Overview, Advances in Materials Science and Engineering, (2013) 1-18.

[7] E. Cuce, P.M. Cuce, C.J. Wood, S.B. Riffat, Toward aerogel based thermal superinsulation in buildings: A comprehensive review, Renewable and Sustainable Energy Reviews, 34 (2014) 273-299.

[8] K. Chen, A. Neugebauer, T. Goutierre, A. Tang, L. Glicksman, L.J. Gibson, Mechanical and thermal performance of aerogel-filled sandwich panels for building insulation, Energy and Buildings, 76 (2014) 336-346. 
[9] X. Wang, L.-L. Lu, Z.-L. Yu, X.-W. Xu, Y.-R. Zheng, S.-H. Yu, Scalable Template Synthesis of Resorcinol-Formaldehyde/Graphene Oxide Composite Aerogels with Tunable Densities and Mechanical Properties, Angewandte Chemie International Edition, 54 (2015) 2397-2401.

[10] R.W. Pekala, Organic Aerogels From The Polycondensation of Resorcinol With Formaldehyde, Journal of Materials Science, 24 (1989) 3221-3227.

[11] R.W. Pekala, F.M. Kong, A Synthetic Route To Organic Aerogels - Mechanism, Structure, and Properties, Journal De Physique, 50 (1989) C433-C440.

[12] X. Lu, M.C. Arduini-Schuster, J. Kuhn, O. Nilsson, J. Fricke, R.W. Pekala, Thermal Conductivity of Monolithic Organic Aerogels, Science, 255 (1992) 971-972.

[13] A.M. ElKhatat, S.A. Al-Muhtaseb, Advances in Tailoring ResorcinolFormaldehyde Organic and Carbon Gels, Advanced Materials, 23 (2011) 2887-2903.

[14] J. Feng, J. Feng, C. Zhang, Shrinkage and pore structure in preparation of carbon aerogels, Journal of Sol-Gel Science and Technology, 59 (2011) 371-380.

[15] X. Lu, R. Caps, J. Fricke, C.T. Alviso, R.W. Pekala, Correlation between structure and thermal conductivity of organic aerogels, Journal of Non-Crystalline Solids, 188 (1995) 226-234.

[16] C. Lin, J.A. Ritter, Effect of synthesis $\mathrm{pH}$ on the structure of carbon xerogels, Carbon, 35 (1997) 1271-1278.

[17] O. Barbieri, F. Ehrburger-Dolle, T.P. Rieker, G.M. Pajonk, N. Pinto, A. Venkateswara Rao, Small-angle X-ray scattering of a new series of organic aerogels, Journal of Non-Crystalline Solids, 285 (2001) 109-115.

[18] C.I. Merzbacher, S.R. Meier, J.R. Pierce, M.L. Korwin, Carbon aerogels as broadband non-reflective materials, Journal of Non-Crystalline Solids, 285 (2001) 210215. 
[19] R. Brandt, R. Petricevic, H. Pröbstle, J. Fricke, Acetic Acid Catalyzed Carbon Aerogels, Journal of Porous Materials, 10 (2003) 171-178.

[20] R. Brandt, J. Fricke, Acetic-acid-catalyzed and subcritically dried carbon aerogels with a nanometer-sized structure and a wide density range, Journal of Non-Crystalline Solids, 350 (2004) 131-135.

[21] T.F. Baumann, J.H. Satcher, A.E. Gash, Preparation of hydrophobic organic aerogels, US20020173554 A1, US7291653 (B2), The Regents of the University of California, Oakland, CA (US), 2007.

[22] S. Mulik, C. Sotiriou-Leventis, N. Leventis, Time-Efficient Acid-Catalyzed Synthesis of Resorcinol-Formaldehyde Aerogels, Chemistry of Materials, 19 (2007) $6138-6144$

[23] S. Mulik, C. Sotiriou-Leventis, Resorcinol-Formaldehyde Aerogels, in: M.A. Aegerter, N. Leventis, M.M. Koebel (Eds.) Aerogels Handbook, Springer New York, 2011, pp. 215-234.

[24] M. Reuß, L. Ratke, Subcritically dried RF-aerogels catalysed by hydrochloric acid, Journal of Sol-Gel Science and Technology, 47 (2008) 74-80.

[25] M. Schwan, L. Ratke, Flexibilisation of resorcinol-formaldehyde aerogels, Journal of Materials Chemistry A, 1 (2013) 13462-13468.

[26] M. Schwan, B. Milow, L. Ratke, Novel superflexible resorcinol-formaldehyde aerogels and combining of them with aramid honeycombs, MRS Communications, 4 (2014) 177-181.

[27] N. Job, R. Pirard, J. Marien, J.-P. Pirard, Porous carbon xerogels with texture tailored by pH control during sol-gel process, Carbon, 42 (2004) 619-628.

[28] J. Laskowski, B. Milow, L. Ratke, Subcritically dried resorcinol-formaldehyde aerogels from a base-acid catalyzed synthesis route, Microporous and Mesoporous Materials, 197 (2014) 308-315. 
[29] S.A. Al-Muhtaseb, J.A. Ritter, Preparation and Properties of ResorcinolFormaldehyde Organic and Carbon Gels, Advanced Materials, 15 (2003) 101-114.

[30] G. Reichenauer, Structural Characterization of Aerogels, in: M.A. Aegerter, N. Leventis, M.M. Koebel (Eds.) Aerogels Handbook, Springer New York, 2011, pp. 449498.

[31] E. Heyn, Short reports from the metallurgical laboratory of the royal mechanical and testing institute of Charlottenburg, The Metallographist, 6 (1903) 39-70.

[32] E.E. Underwood, Quantitative stereology, Addison-Wesley Pub. Co., Reading, MA, 1970.

\section{Figure captions}

Fig. 1. Representative RF aerogels prepared at $\mathrm{pH} 7$ (left) and $\mathrm{pH} 6.5$ (right), respectively....... 6

Fig. 2. Increase of envelope density with higher resorcinol amount........................................ 7

Fig. 3. Dependence of radial shrinkage on solid content. Acidified samples show less shrinkage than gels prepared at $\mathrm{pH} 7$.

Fig. 4. Microstructure of aerogels prepared via conventional base catalysis (a and c) and baseacid catalysis ( $b$ and $d)$.

Fig. 5. Specific surface area measured by nitrogen adsorption of RF aerogels. Upon acidification the average surface area drops from $500-680 \mathrm{~m}^{2} \cdot \mathrm{g}^{-1}$ to $200-380 \mathrm{~m}^{2} \cdot \mathrm{g}^{-1}$. 7

Fig. 6. Increase of compression modulus with higher R:W molar ratio 